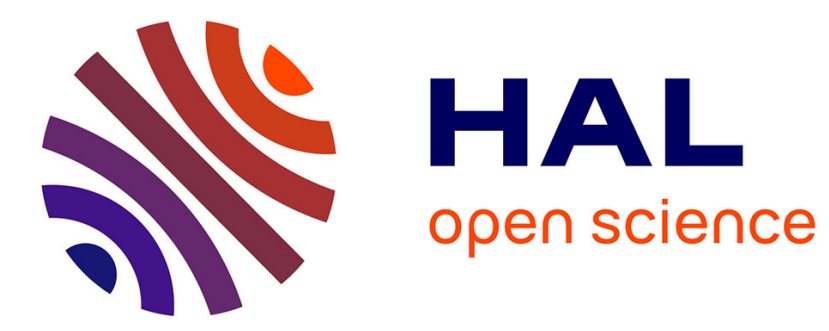

\title{
Dusty plasma for nanotechnology
}

L Boufendi, M Ch Jouanny, E Kovacevic, J Berndt, M Mikikian

\section{To cite this version:}

L Boufendi, M Ch Jouanny, E Kovacevic, J Berndt, M Mikikian. Dusty plasma for nanotechnology. Journal of Physics D: Applied Physics, 2011, 44 (17), pp.174035. 10.1088/0022-3727/44/17/174035 . hal-00613288

\section{HAL Id: hal-00613288 \\ https://hal.science/hal-00613288}

Submitted on 4 Aug 2011

HAL is a multi-disciplinary open access archive for the deposit and dissemination of scientific research documents, whether they are published or not. The documents may come from teaching and research institutions in France or abroad, or from public or private research centers.
L'archive ouverte pluridisciplinaire HAL, est destinée au dépôt et à la diffusion de documents scientifiques de niveau recherche, publiés ou non, émanant des établissements d'enseignement et de recherche français ou étrangers, des laboratoires publics ou privés. 


\title{
Dusty plasma for nanotechnology
}

\section{Boufendi, M. Ch. Jouanny, E. Kovacevic, J. Berndt, and M. Mikikian GREMI, Orleans Univeristy, 14 Rue d'Issoudun, BP 6744, 45067 Orleans Cedex 2, France}

\begin{abstract}
During years dust particles formed in plasmas used for microelectronic technologies were considered as an important source of irremediable defects. They grow in the gas phase through homogeneous chemical reactions and remain trapped in the plasma gas phase due to the negative charge they acquire by electron attachment. The earlier formed particles are in certain conditions crystallites with 2 to $4 \mathrm{~nm}$ in diameter when operating at room temperature. These nanocrystallites can be used as quantum dots for many applications in nanoelectronics (Single Electron Devices,...), photoluminescent devices, optical amplification and biomedical applications. We show here that dusty plasmas can be a very efficient tool for the synthesis of these nano-objects. By using its physical properties we showed that it is possible to control the synthesis of nanocrystallites or nanoparticles with well defined sizes. The sizes of the earlier nanocrystallites can also be tuned by varying the plasma physical parameters.
\end{abstract}

PACS numbers : 52.77.-j, 81.07.-b, 81.16.-c 


\section{Introduction}

In the last two decades Nanoscience and Nanotechnologies became more and more important and found an increasing number of applications. One example concerns the discovery of the photoluminescence of porous silicon in the earlier 90's which launched an intense research activity in different directions [1-7]. It was found that this photoluminescence effect was due to the presence of silicon nanocrystals embedded in different kinds of matrixes. Other technological domains focused their effort on nanomaterial because of their unique mechanical properties such as the hardness and low friction coefficient. [8, 9]. These nanomaterials (size ranging between $1 \mathrm{~nm}$ to $100 \mathrm{~nm}$ ) are also recognised as very promising for energy production (photovoltaic [3, 10, 11,] in the second and third generation), hydrogen conversion (nanocatalysts) [12] and thermoelectricity [13]. In fact, plasma synthesised nanoparticles, with $100 \mathrm{~nm}$ in diameter, can exhibit a large specific area more than $100 \mathrm{~m}^{2} / \mathrm{g}$ [10].

Recently thin silicon films grown, with a significant contribution of nanoparticles coming from the plasma, have been found to exhibit improved properties of transport, mobility of the charge carriers, material stability and a rather high optical gap as compared to $a$-Si:H [11]. These films have been described as a mixture of amorphous and ordered material and are called polymorphous Si (pm-Si:H) or as nanostructured Si (ns-Si:H) [3, 14-17]. Active studies are conducted to use nanocrystallites as quantum dots in thin layers in order to fabricate very high efficiency solar cells $[18,19]$. Silicon material by itself is not efficient as light emitter as it is an indirect-bandgap semiconductor. L. Pavesi and his co-workers however demonstrated that if silicon nanocrystals or quantum dots are embedded in a silicon dioxide matrix there is a significant optical gain in both transmission and waveguide configurations [20]. In the same way nanocrystallites are also synthesised and embedded in the $\mathrm{SiO}_{2}$ channel between the source and the drain, as quantum dots, for Single electron devices [5, 21-25] and photo and electroluminescent devices [26-28]. More recently it was found that nanoparticles can also have very interesting biomedical applications as for example for cancer treatment or cell culture [29-33].

In principal there are several different methods that can be used for the synthesis of the nanocrystallites especially low pressure plasmas operating with reactive gases. In this contribution we want to show that low pressure dusty plasmas can be very efficient to produce nanocrystals with well defined sizes. This requires accurate knowledge of the discharge and plasma properties and also the time evolution of the different reactive species 
number densities [34-39]. If so the process will be well controlled in terms of dust particle nucleation and growth.

The use of plasmas for the production of nanoparticles in general benefited from the very important research activity devoted to dusty plasmas in the last decade [40-42]. This considerable work was initially motivated by the highly unwanted generation of dust particles in plasma processes used for the production of integrated circuits. The observations reported by G. Selwyn [43] showed that the process itself produces huge contamination even if it is located in a clean room. On the other hand, the observations performed in the middle of 80 's on the black spots in Saturn rings called "spokes" were here to reinforce this interest and contributed to launch this very active research [44].

Among all the aspects related to the charging and dynamics of dust particles in plasmas much effort has been made to understand the growth mechanisms of these particles and their detection in the gas phase in the plasma when their mean size is in the nanometre range.

The first part of the paper will be devoted to the description of the experimental set up and the different diagnostic tools and methods we used to follow in real time the nucleation and growth of the dust particles in the plasma gas phase. The second part concerns the results related to the dust particle growth mechanisms and their discussion. A conclusion will summarize and emphasize the most important aspects of this phenomenon.

\section{Experimental set up}

Dust particles formation has been studied in various conditions and plasmas. In this contribution we will focus on results obtained in capacitively coupled capacitive discharges driven by a radiofrequency (RF) excitation. Our experimental setup was actually described in detail in previous articles [45]. The RF discharge is produced in a grounded cylindrical box (13 cm inner diameter) equipped with a shower-type RF powered electrode (Fig.1). The bottom of the box is closed with a $20 \%$ transparent grid which allows a vertical laminar gas flow. The discharge structure is surrounded by a cylindrical oven which can be used to change the gas temperature from room temperature up to $200{ }^{\circ} \mathrm{C}$. In order to decrease the gas temperature liquid nitrogen is flowed through copper tube surrounding the vacuum vessel. Three vertical slits ( $2 \mathrm{~mm}$ wide, $4 \mathrm{~cm}$ high) allow optical access to the plasma at $0^{\circ}, 90^{\circ}$, and $180^{\circ}$ around the chamber. The whole system is enclosed in a vacuum vessel of $30 \mathrm{~cm}$ in height and inner diameter. Three optical viewports on the vacuum vessel $(5 \mathrm{~cm}$ in diameter and $90^{\circ}$ apart) are aligned with the slits. 
The discharge and the plasma are characterized through the time evolution of the amplitudes of the third harmonic of the discharge current and the self bias and the electron density. These three parameters are directly related to the discharge impedance. They can allow the detection of the appearance of dust particles in the gas phase [46]. In fact as soon as the dust particles appear in the plasma the electron collision frequency is affected and the electron flux to the electrode is modified and thus the electrical parameters are affected. The self bias and the discharge current are respectively measured using current and voltage probes. The third harmonic of the current is extracted and its amplitude is followed depending on the time. The electron density is measured using the discharge box as a microwave resonant cavity. Two antennas are placed inside the box on the grounded electrode. One of them is connected to a microwave generator and the second one is connected to a digital scope through a detection diode. The shift of the resonance frequency, induced when the plasma is turned on, is used to determine the electron density from the expression given below.

$$
n_{e}=\frac{2 m_{e} \varepsilon_{0}(2 \pi f)^{2} \Delta f}{e^{2} f_{0}}
$$

Where $\mathrm{f}_{0}$ and $\mathrm{f}$ are the resonance frequencies without and with a plasma respectively, $\Delta \mathrm{f}$ the frequency shift, $\mathrm{m}_{\mathrm{e}}$ the electron mass, e the elementary charge and $\varepsilon_{0}$ the permittivity of vacuum. This diagnostic allows us to follow the time evolution of the electron density during the formation of the negative ions which are the seeds for the dust particle formation $[47,48]$.

These electron density measurements are correlated with the discharge and plasma electrical parameters. This correlation allows the control of the synthesis process of the dust particles at their different stage of formation and underlines the role of the different physical parameters of the discharge.

\section{Particle nucleation and growth}

The Formation of Si nanoparticles in low pressure cold plasmas has been studied by different groups all around the world. An exhaustive review of this research [40] shows that growth phenomena, from monomer precursors to large size particles, are rather well elucidated for the typical conditions of pressure, power density and diffusion lengths relevant for PECVD technologies. This process involves successive steps: nucleation leading to the formation and accumulation of few nanometre sized (100-1000 Si atoms) dust particles; 
agglomeration of these "protoparticles" when critical densities are reached (few $10^{11} \mathrm{~cm}^{-3}$ ); further growth by radical sticking process when charging effects prevent further agglomeration. The first step and its limiting transition to the agglomeration phase are key points when nanostructured thin films are grown with the inclusion of a significant volume fraction of nanocrystals in the amorphous matrix. It is a fast $(10-100 \mathrm{~ms})$ process leading to the formation of $\mathrm{nm}$ sized $(2-4 \mathrm{~nm})$ particles, mainly neutral, with low hydrogen content and a monocrystal-like structure. Figure 2 summarises this process.

\section{Results and discussions}

\section{a) Dust particle detection}

In order to detect and to follow the nucleation and growth of dust particles in the plasma gas phase different methods have been developed and used. Laser light scattering (LLS) was the most used technique to detect and size the nanoparticles while they are growing up. However this technique is very limited when the particle size is bellow about $30 \mathrm{~nm}$ due to the very low scattering cross section which depends on the sixth power of the particle radius [40]. Many different techniques have been developed in order to improve the scattered intensity and thus detect smaller particles [49]. Researcher working on hydrocarbon compounds combustion used Laser Induced Incandescence (LII) to detect and size the soot particles. This method is based on the fact that dust particles heated up for example by Infrared lasers can irradiate as a black body. The time evolution of the emitted radiation contains information about their size and concentration [50]. The irradiated intensity is much higher compared to the scattered one. This means that LII is more efficient to detect small particle than LLS [51]. This technique has been improved by using a pulsed high power excimer laser in order to evaporate the dust nanoparticles and to create microplasmas with their vapour. This method was called "Laser induced particle explosive evaporation" (LIPEE) [45]. It enables the detection of the earlier nanocrystallites which are formed in the first phase of the dust particle formation process.

However all these techniques need view ports and are very difficult to handle. Most of the industrial reactors have no windows and thus it is not possible to shine the interior with a laser beam. That is the reason for the development of methods based on the use of the discharge and plasma physical characteristics [46]. Their time evolution is well correlated with all events that can occur in the plasma gas phase such as the formation of dust or nanoparticles presence. In fact when they are formed or injected in the plasma dust particles attach electrons and thus cause a decrease of the electron density. This drop has consequences on the 
discharge current collected by the cathode and also on the self bias voltage. More precisely the time evolution of the amplitude of the harmonics of the current (or voltage) which appear due to the nonlinear relationship between the voltage drop through the sheath and the current is more sensitive to these events.

Figure 3 shows a time evolution of the amplitudes of the fundamental component and the third harmonic of the discharge current for a pristine argon plasma (Fig. 3a) and a dust forming one (Fig. 3b). The drastic changes in this last figure are clearly related to the dust particles. In the first hundred milliseconds the change is very small. This means that most of the first nanoparticles are neutral and the change is due to a modification of the electron collision frequency. However the second important drop is due to electron attachment on the particles. The slight increase at the end of this first part of the curve is an indication of the beginning of the agglomeration phase [52]. The amplitude of the $3^{\text {rd }}$ harmonic reaches a constant value at around 4 seconds which correspond to the end of the agglomeration phase and the beginning of the phase where the dust particles continue to grow by molecular radical sticking on their surface [53].

In order to validate these observations we collected dust particles at different times and analyzed them by means of electron microscopy. Figure 4 gives scanning electron microscope micrographs of particles collected before and after the beginning of the agglomeration phase. From this figure we can clearly see that single nanoparticles synthesis can be well controlled through the time evolution of the discharge current harmonics [54].

\section{b) Effect of the gas temperature on the dust particle formation.}

Figure 5 gives the time evolution of the amplitude of the third harmonic when the gas temperature is varied from room temperature to $150{ }^{\circ} \mathrm{C}$. The temperature slows down the growth kinetics and mainly the first phase that becomes longer. It also emphasizes a transient phase during the agglomeration one which is related to the formation and accumulation of 10 $\mathrm{nm}$ particles in the plasma gas phase. From this observation we can see that for high temperature the formation of the nanocrystallites is delayed. This can be a good way to monitor the volume fraction of these nanocrystallites in the amorphous matrix during the growth of polymorphous silicon [55]. The decrease of the amplitude of the harmonic during the first phase indicates the formation and the accumulation of the nanocrystallites. When their number density reaches its critical value (few $10^{11} \mathrm{~cm}^{-3}$ ) which corresponds to a mean distance between the nanoparticles of about $1 \mu \mathrm{m}$ the agglomeration phase starts. This 
indicates that even if layers are deposited at higher temperatures nanocrystallites can be formed but their concentration cannot reach its critical value.

c) Correlation of these observations with the time evolution of the plasma parameter.

Among the plasma characteristics the electron density $n_{e}$ is the most sensitive one to the dust particles formation due to the electron attachment that occurs. Figure 6 gives the time evolution of the electron density for one second of plasma duration. On the same figure we plotted also the time evolution of the self bias voltage $V_{D C}$. A very good correlation between both signals can be seen. The $\mathrm{V}_{\mathrm{DC}}$ drastic drop is clearly related to the drop of the electron density that is related to the attachment on the dust particles. The insert shows a zoom of the electron peak at the ignition of the plasma. This peak is an indication of the negative ions which are the basis for the formation of the dust particles $[47,48,56]$. The time constant for their formation is about $6 \mathrm{~ms}$. Total negative charge accumulated on the first nanocrystallites during their formation and accumulation up to the beginning of the agglomeration phase remains constant and corresponds to the drop of the electron density when the negative ions are formed.

The effect of the gas temperature on the growth kinetics can also be observed on the electron density evolution. Figure 7 gives the time evolution of $n_{e}$ for four different gas temperatures. The insert shows that the first $n_{e}$ peak is not affected. This means that the gas dissociative attachment cross section for the formation of the negative ions is not affected. However, the chemical reactions which are behind the growth of the nanocrystallites are severely affected $[57,58]$.

\section{Conclusion}

In this contribution we gave a short overview about the use of silicon nanocrystallites in nanotechnology and how low pressure cold plasmas can be used to synthesis the crystals and also nanoparticles. We presented results obtained on the nucleation and growth of silicon nanoparticles and emphasized the different phases of this process which occurs in the plasma gas phase. Following the time evolution of the harmonics of the discharge current or the self bias gives the possibility to monitor and control the synthesis of dust nanoparticles with desired sizes and with monodispersed size distribution. The use of these techniques for other chemistries is at the present time underway and the results will be published very soon. These results open the way for different application from nanoelectronics to biomedical ones. 
However some aspects related to the manipulation of the nanoparticles, tailored in the gas phase of the plasma, need to be studied. In fact for some applications deposition of the nanocrystallites in dedicated location is required. The particles released when the plasma is turned off fall down randomly on the substrate. Their manipulation can be achieved through the residual charge they keep in the afterglow as shown in preliminary works $[59,60]$. This charge can allow their manipulation either in the plasma or in the afterglow phase.

The growth phases of the nanocrystallites have to be studied in order to better understand the role of the different evolved species in the definition of their crystalline structure. The role of hydrogen has to be clarified as suggested in some theoretical simulations [61]. Also some intermediate nanoclusters can exhibit very interesting properties that can be studied.

The nanoparticles in question in this paper can exhibit big risks for human health. This risk is related to their size, their specific area, their chemical composition, their crystalline structure and also to their morphology. Much work has been performed for in situ detection and sizing of nanoparticles based on the use of laser light scattering or heating. However due to the very low scattering cross section new more efficient methods and tools have to be developed for this range of nanoparticle sizes. 
References

1- H. Takagi, H. Ogawa, Y. Yamazaki, A. Ishizaki, and T. Nakagiri, Appl. Phys. Lett. 56, 2379 (1990).

2- L. T. Canham, Appl. Phys. Lett. 57, $1046 \_1990 \_$.

3- P. Roca i Cabarrocas, P. Gay, and A. Hadjadj, J. Vac. Sc. Technol. A 14, 655 (1996).

4- T. Baron, F. Martin, P. Mur, C. Wyon, M. Dupuy, C. Busseret, A. Souifi, and G. Guillot, Applied Surface Science 164, 29-34 (2000).

5- G. Gay, D. Belhachemi, J. P. Colonna, S. Minoret, P. Brianceau, D. Lafond, T. Baron, G. Molas, E. Jalaguier, A. Beaurain, B. Pelissier, V. Vidal, and B. De Salvo, Appl. Phys. Lett. 97, 152112 (2010).

6- L. Khriachtchev, M. Räsänen, S. Novikov, and J. Sinkkonen, Appl. Phys. Lett. 79, 1249 (2001).

7- S. Oda, Materials Science and Engineering: B 101, 19 (2003).

8- S. Vepřek, Pure \& Appl. Chem., Vol. 68, No. 5, pp. 1023-1027, (1996).

9- T. Gries, L. Vandenbulcke, J. N. Rouzaud, and S. de Persis, Plasma Sources Sci. \& Technol. 19, 025015 (2010)

10- Chin-Yi Liu, Zachary C. Holman, and Uwe R. Kortshagen, Nano Lett. 9, 449 (2009).

11- C. Longeaud, J. P. Kleider, P. Roca i Cabarrocas, S. Hamma, R. Meaudre, and M. Meaudre, J. Non-Cryst. Solids 227-230, 96 (1998).

12- F. Vivet, A. Bouchoule, and L. Boufendi, J. Appl. Phys. 83, 7474 (1998).

13- E. Serrano, K. Li , G. Rus, and J. García-Martínez "Nanotechnology for the Energy Challenge” Ed. J. García-Martínez, (WILEY-VCH Verlag GmbH), (2009).

14- A. Hadjadj, Beorchia A, P. Roca i Cabarrocas, L. Boufendi, S. Huet, and J. L. Bubendorff, J. of Phys. D-Appl. Phys. 34, 690 (2001).

15- G. Viera, S. Huet, M. Mikikian, and L. Boufendi, Thin Solid Films 403, 467 (2002).

16- M. Shiratani, K. Koga, S. Ando, T. Inoue, Y. Watanabe, S. Nunomura, and M. Kondo, Surface Coating Techology 201, 5468 (2007).

17- A. Martí, L. Cuadra, and A. Luque, Physica E 14, 150 (2002).

18- G. Wei and S. R. Forrest, Nano Lett., Vol. 7, No. 1, 2007

19- Chin-Yi Liu, Z. C. Holman, and U. R. Kortshagen Nano Lett., 2009, 9 (1),

20- L. Pavesi, L. Dal Negro, C. Mazzoleni, G. Franzò, and F. Priolo, Nature 408, 440 (2000).

21- S. Huang et al IEEE Nanotech 2004 
22- A. Dutta, Y. Hayafune, and S. Oda, Jpn. J. Appl. Phys. 39, L855 (2000),

23- F. Yun, B. J. Hinds, S. Hatatani, S. Oda, Q. X. Zhao, and M. Willander, Thin Solid Films 375, 137 (2000).

24- M. Bedjaoui et B. Despax, Thin Solid Films 518, 4142 (2010).

25- Kai-Yuan Cheng, R. Anthony, U. R. Kortshagen, and R. J. Holmes, Nano Lett. 10, 1154 (2010).

26- I. Stenger, Abramov, A. Barthou, Th. Nguyen-Tran, A.Frigout, P Roca i

Cabarrocas, Appl. Phys. Lett. 92, 241114 (2008).

27- L. Mangolini, E. Thimsen, and U. R. Kortshagen, Nano Lett. 5, 655 (2005).

28- R. Anthony, and U. R. Kortshagen, Phys Rev. B 80, 115407 (2009).

29- B. Samanta, H. Yan, N. O. Fischer, J. Shi, D. J. Jerry, and V. M. Rotello, J. Mater.

Chem. 18, 1204 (2008)

30- A. M. Boies, J. T. Roberts, S. L. Girshick, B. Zhang, T. Nakamura, and A. Mochizuka Nanotechnology 20, 295604 (2009).

31- Y. He, C.Fan, Shuit-Tong Lee, Nano Today 5, 282 (2010).

32- C. M. Hessel, M. R. Rasch , J. L. Hueso , B. W. Goodfellow,V. A. Akhavan, P. Puvanakrishnan, J. W. Tunnel, and B. A. Korgel, small 6, 2026 (2010)

33- S. Xu,*, J. Long, L. Sim, C. Hoong Diong, K. Ostrikov, Plasma Processes and Polymers 2, 373 (2005).

34- GS. Oehrlein, "Plasma processing of electronic materials”, Berlin: Springer, (2003).

35- S. V. Vladimirov, K.Ostrikov, Phys Rep, 393:175 (2003).

36- K. Ostrikov, Rev Mod Phys, 77:489 (2005)

37- K. Ostrikov, J.D. Long, P.P. Rutkevych, S. Xu, Vacuum 80, 1126 (2006).

38- P. P. Rutkevych, K. Ostrikov, S. Xu, S. V. Vladimirov, J. Appl. Phys. 96, 4421 (2004).

39- I. B. Denysenko, S. Xu,a) J. D. Long, P. P. Rutkevych, N. A. Azarenkov, and K. Ostrikov, J. Appl. Phys. 95, 2713 (2004).

40- A. Bouchoule (ed) "Dusty Plasmas, Physics, Chemistry and Technological Impacts in Plasma Processing” (New York: Wiley), (1999).

41- K. Ostrikov, Rev. Mod. Phys. 77, 489 (2005)

42- K. Ostrikov, A. B. Murphy, J. of Phys. D: Appl. Phys. 40, 2223 (2007).

43- G. S. Selwyn, J. Singh, and R. S. Bennet J. Vac. Sci. Technol. A 7 2758, (1989).

44- C. Goertz, Rev. Geophys. 27, 271 (1989). 
45- L. Boufendi, J. Hermann, A. Bouchoule, B. Dubreuil, E. Stoffels, W. Stoffels, and M. L. de Giorgi, J. Appl. Phys. 76, 148 (1994).

46- L. Boufendi, J. Gaudin, S. Huet, G. Viera and M. Dudemaine, Appl. Phys. Lett. 79, 4301 (2001).

47- A A Howling, L Sansonnens, J-L Dorier and Ch Hollenstein, J. Phys. D: Appl. Phys. 26, 1003 (1993).

48- J. Berndt, E. Kovacevic, I. Stefanovic, and L. Boufendi, J. Appl. Phys. 106, 063309 (2009).

49- M. Shiratani, and Y. Watanabe, The revue of Laser Engineering 26, 449 (1998).

50- A. Boiarciuc et al Applied Physics B83, 413, (2006).

51- W. W. Stoffels, E. Stoffels, G. W. M. Kroesen, and F. J. Dehoog Appl. Phys Letter 74, 2959 (1993).

52- M. Cavarroc, M. Ch. Jouanny, K. Radouane, M. Mikikian and L. Boufendi, J. Appl. Phys. 99, 064301 (2006).

53- L. Boufendi, and A. Bouchoule, Plasma Sources Sci. and Technol. 3, 262 (1994).

54- M. Cavarroc, M. Mikikian, G. Perrier, L. Boufendi, Appl. Phys. Lett. 89, 013107 (2006).

55- G. Viera, S. Huet, E. Bertran, and L. Boufendi, J. Appl. Phys. 90, 4272 (2001).

56- Berndt, J., Kovacevic, E., Stefanovic, I., Stepanovic, O. Hong, S. H. Boufendi, L., and Winter, J., Contributions to Plasma Physics 49, 107 (2009).

57- U. Bhandarkar, U. Kortshagen, and S. L. Girshick, J. Phys. D: Appl. Phys. 36, 1399 (2003)

58- A. Fridman, L. Boufendi, T. Hbid, B. Potapkin, and A. Bouchoule, J. Appl. Phys.79, 1303 (1996).

59- L. Couëdel, M. Mikikian, L. Boufendi, and A. A. Samarian, Phys. Rev. E 74, 026403 (2006).

60- L. Couëdel, A. A. Samarian, M. Mikikian, and L. Boufendi, Physics Of Plasmas 15, 063705 (2008).

61- Q. Brulin, N. Ning, H Vach, J. Non-Cryst. Solids 352, 1055 (2006). 


\section{Figure Captions}

Fig. 1: Schematic representation of the experimental set-up

Fig. 2: Different steps of nanoparticles formation process

Fig. 3: Time evolution of the amplitudes of the fundamental and third harmonics of the discharge current in (a) pristine argon plasma and (b) silane based dust forming plasma.

Fig. 4: Nanoparticles collected (a) before and (b) after the beginning of the agglomeration phase.

Fig. 5: Time evolution of the amplitude of the third harmonic for different gas temperatures.

Fig. 6: Time evolution of the electron density.

Fig. 7: Time evolution of the electron density for different gas temperatures. 


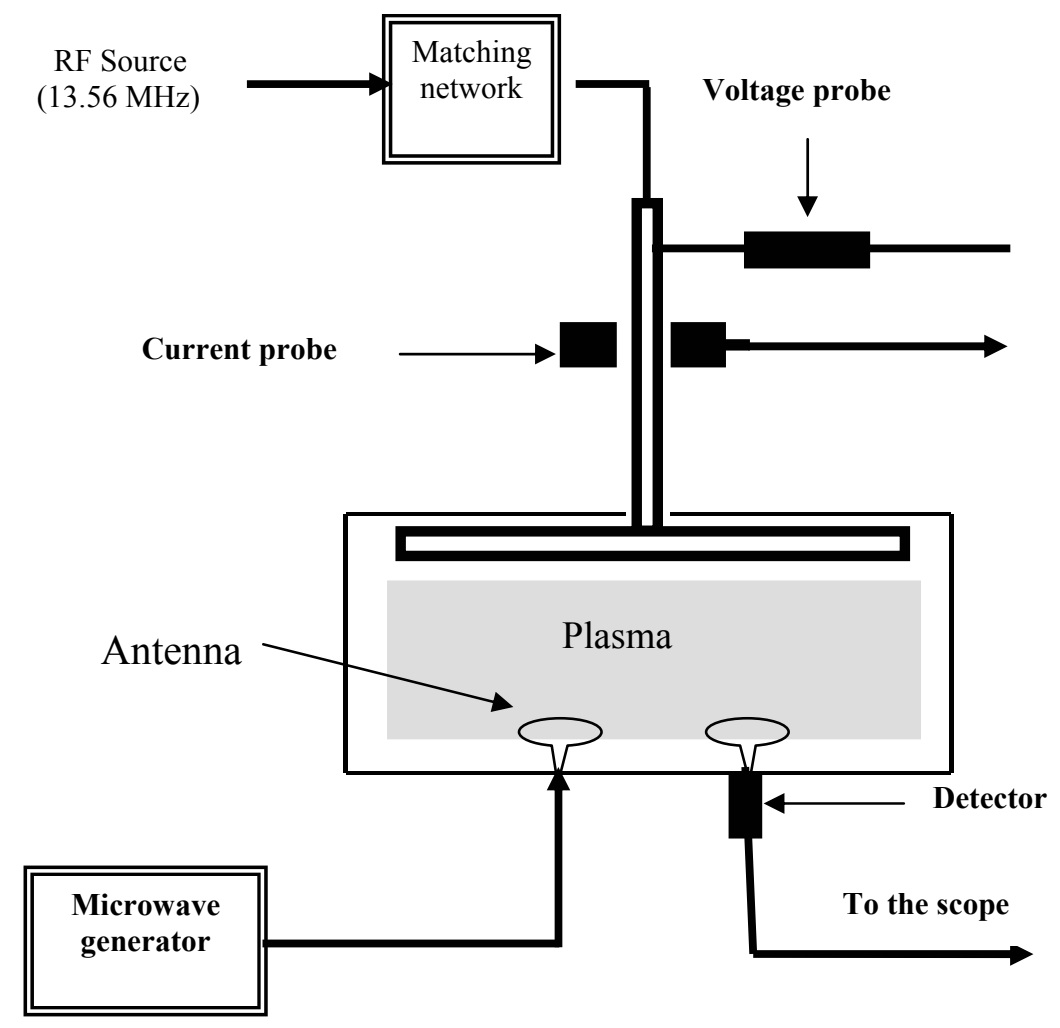

Figure 1: 


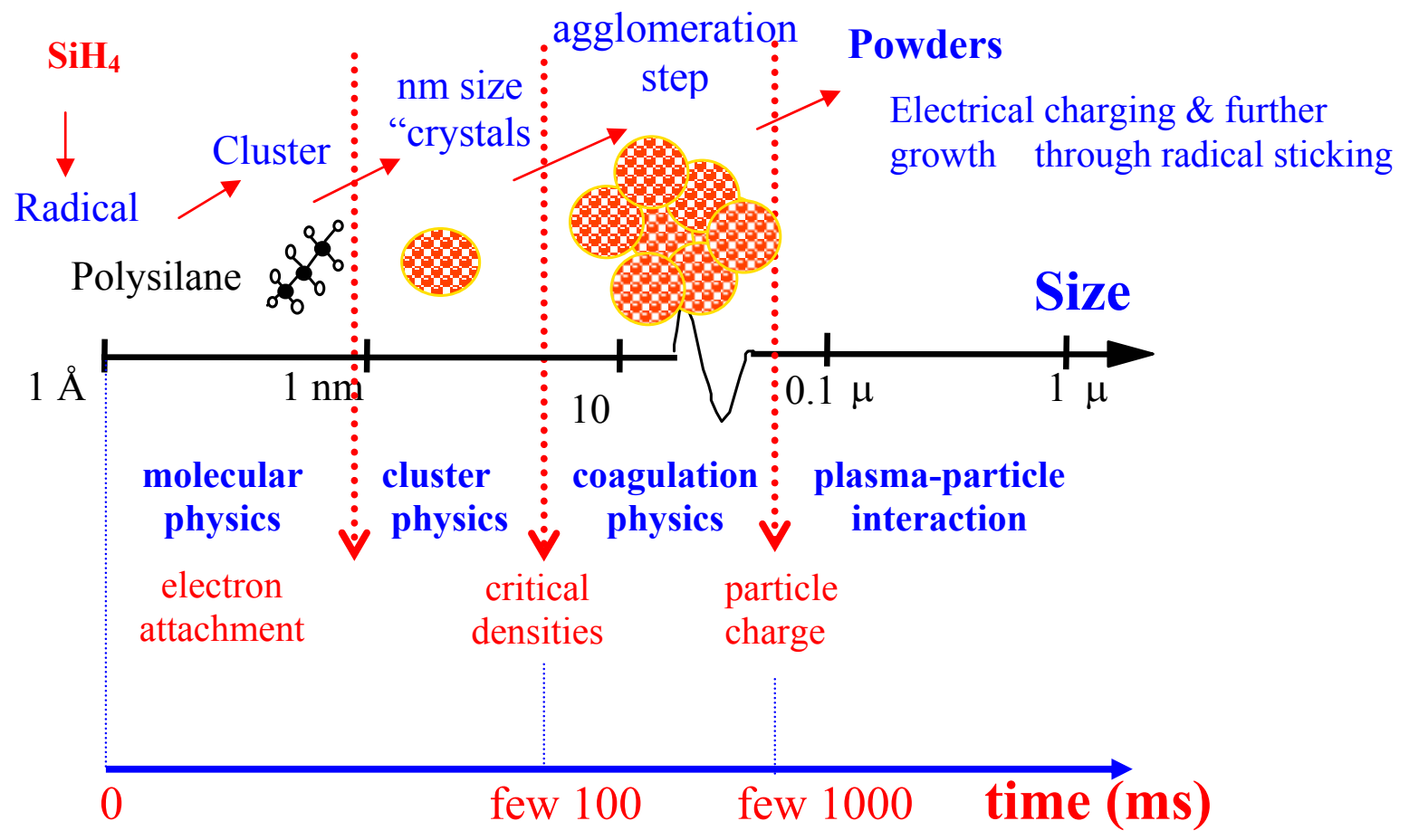

Figure 2: 

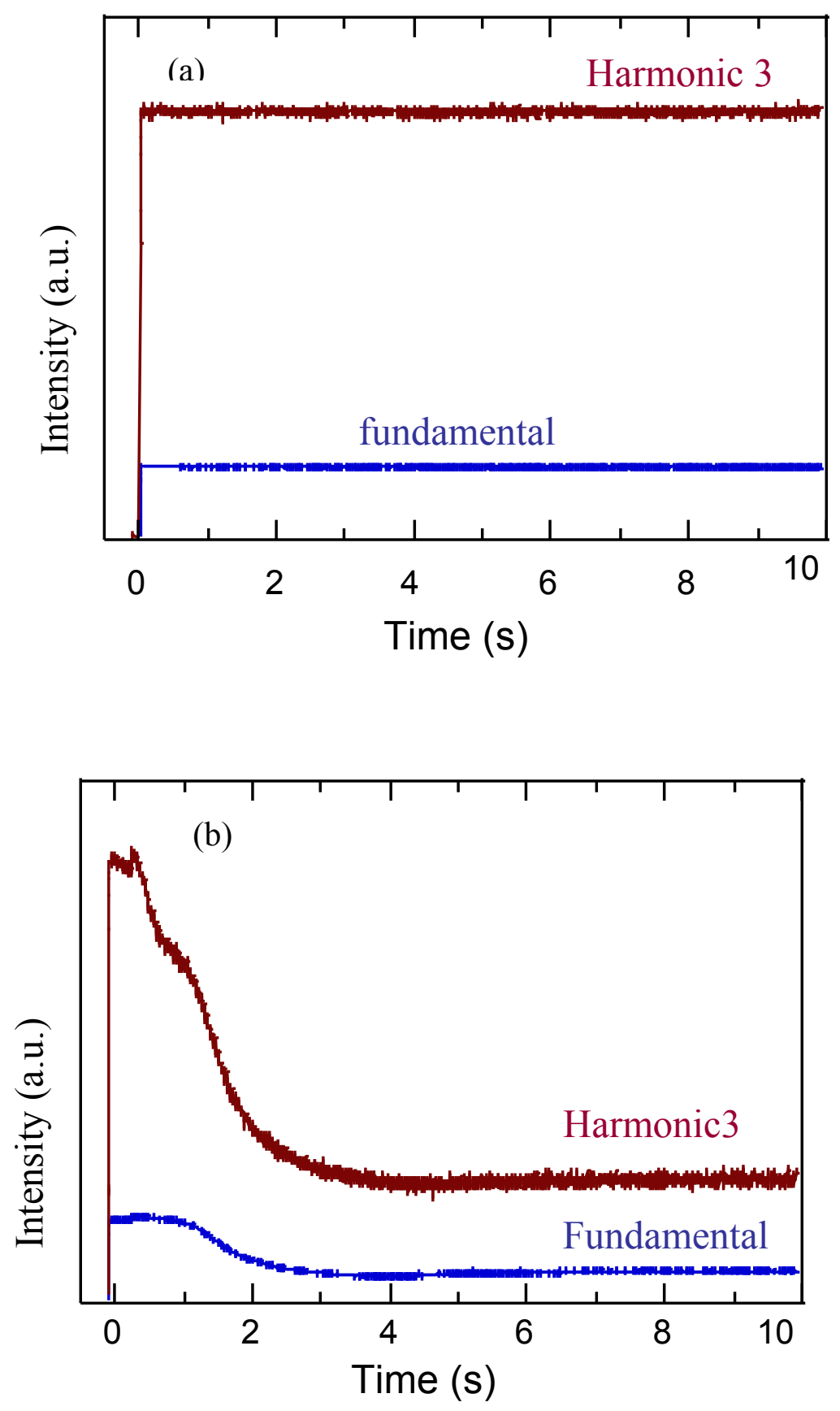

Figure 3 

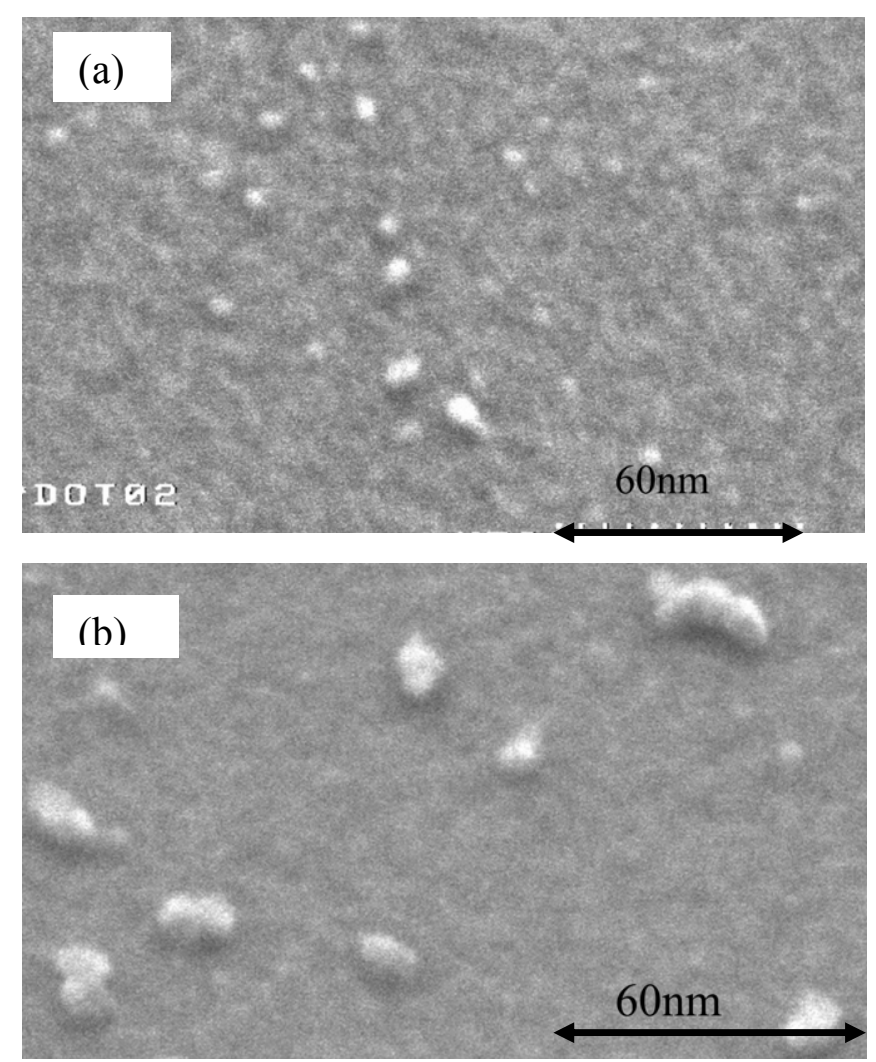

Figure 4 


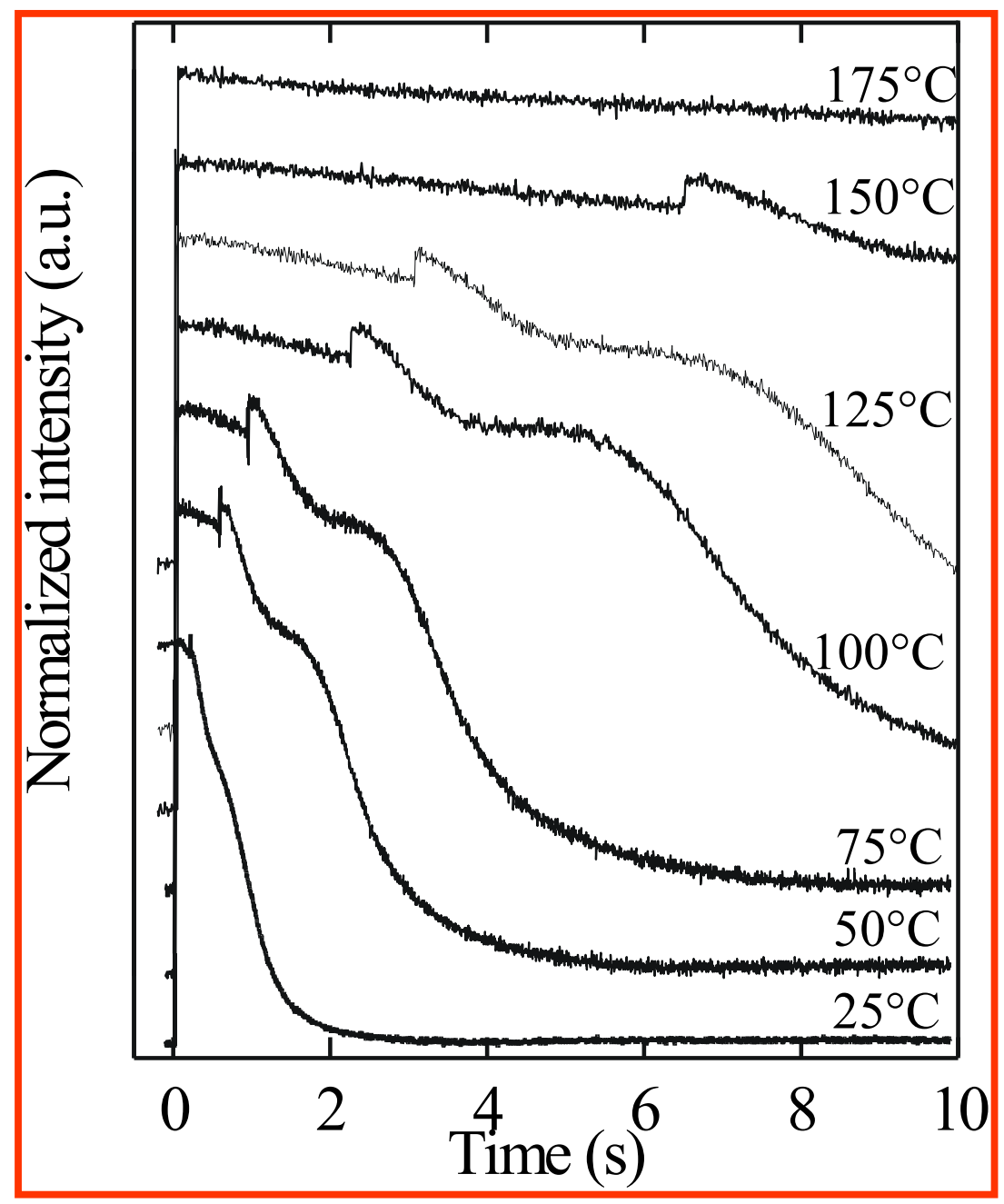

Figure 5 


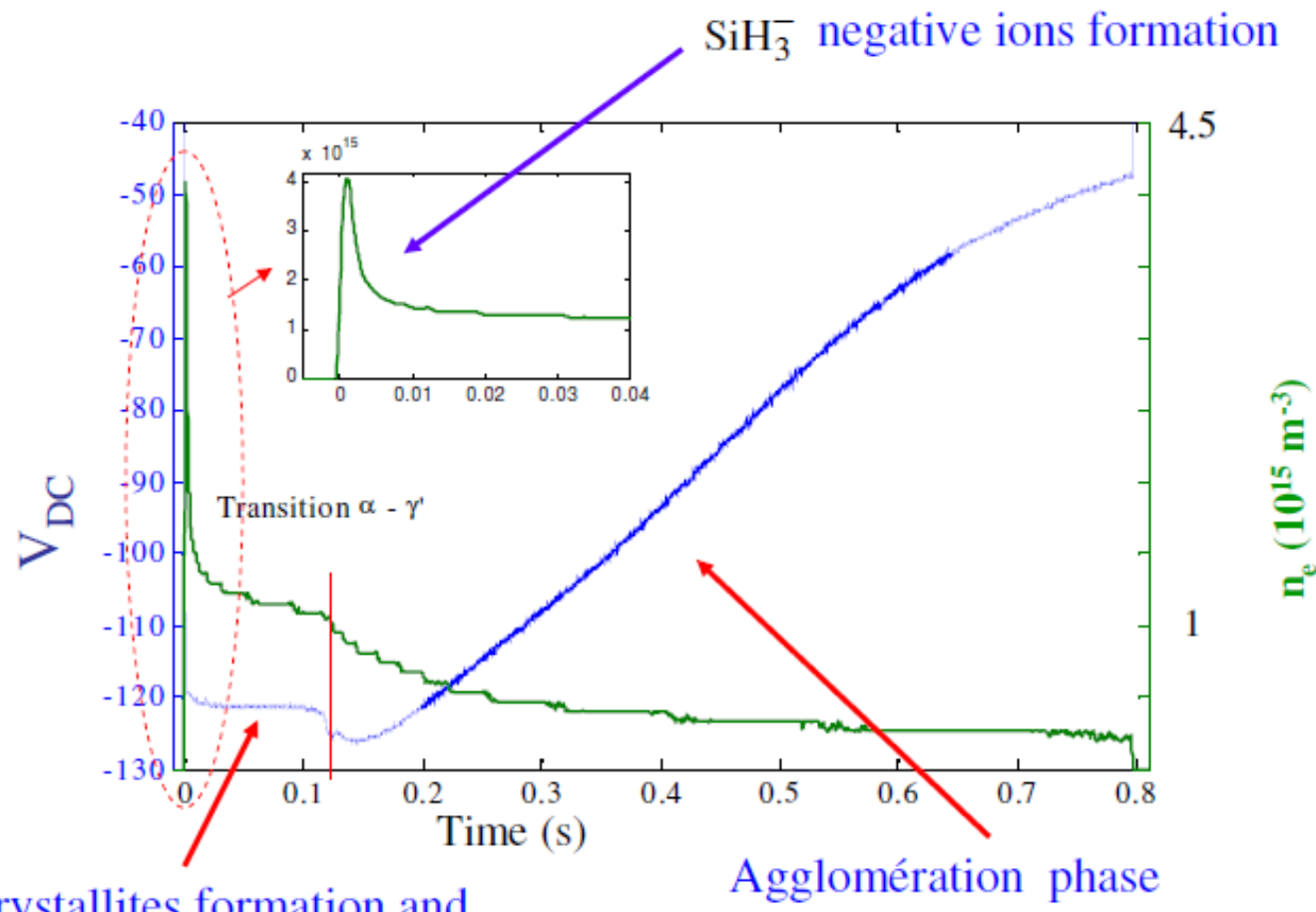

Nanocrystallites formation and Agglomération phase accumulation

Figure 6 


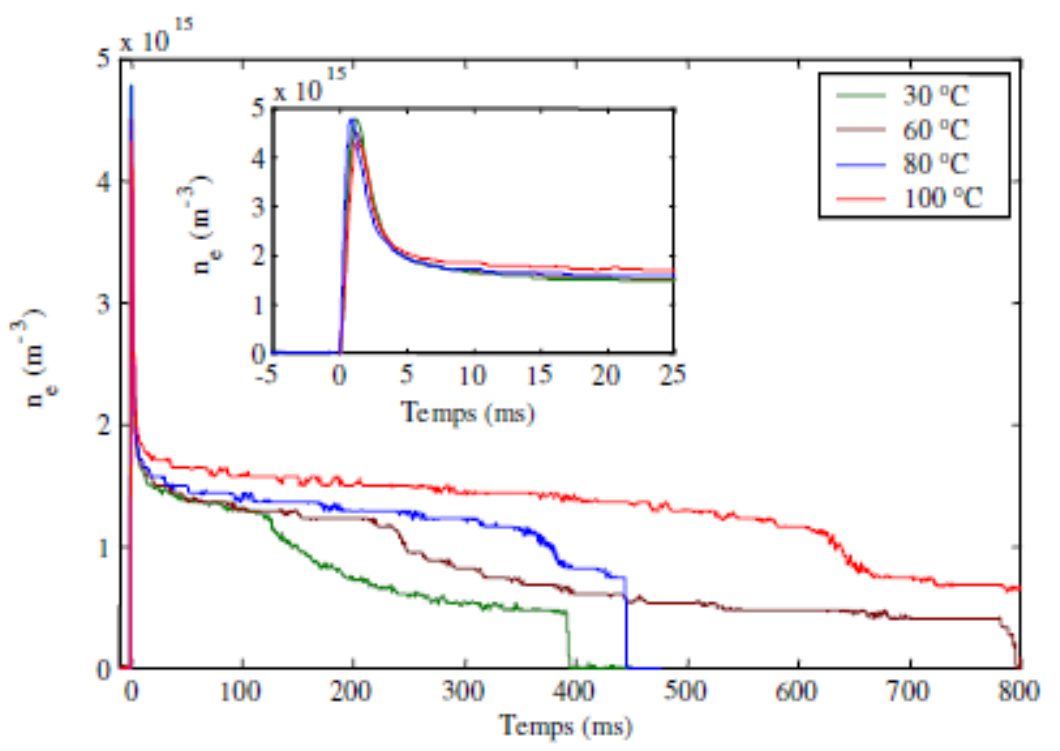

Figure 7 